The chapters are well written and conclude with a study of metastases in man, there is a chapter on the diagnosis of metastases by various $\mathrm{X}$-ray techniques, including scans. The final chapter deals with the usefulness of measuring various antigen; such as carcino-embryonic antigen (CEA). Unfortunately the estimation of such antigen in early detection of tumour has not yet proved very reliable, but is obviously a promising field for future research. So far, the only success in this field is the use of CEA in monitoring the progression of carcinoma of the colon.

This book is excellent for the person who is interested in metastases and wishes to be stimulated into thinking about possible reasons for their behaviour.

\section{Health Care in a Changing Setting: the U.K. Experience}

Ciba Foundation Symposium 43 (new series). Pp. viii + 188, hard cover, illustrated. Excerpta Medica, Amsterdam, 1976. Dfl 37.00, U.S. \$14.25.

It is not given to us all to become famous, but in this busy world there are few who, metaphorically speaking, need 'waste their sweetness on the desert air' or, in less poetical language, 'lead a useless life'. So begins the 1901 edition of Mrs Beeton's Cookery Book. I am sure that it was in the minds of the C.I.B.A. Foundation when they arranged their symposium on 'Health Care in a Changing Setting: the U.K. Experience' December 1975 (published August 1976), to ensure that the deliberations of the participants were not so wasted. To return to Mrs Beeton, 'In the hands of a good cook a joint (with the exception of veal) will always yield enough gravy to serve with it, but for game, poultry and other dishes, it must be made'. It was decided that Ruth Porter (organizer) and David W. Fitzsimons should edit the proceedings of this C.I.B.A. Foundation symposium. The reader has to decide how far their working material was veal, game or poultry or the viands with a more substantial gravy yield.

Certainly there are several solid contributions such as that of Leslie Paine, House Governor and Secretary of the Bethlem Royal Hospital, 'In a nutshell', he says, 'I am suggesting that our new system has perhaps overlooked the single fact that patients come to health services to be treated and not administered'. Breath-taking stuff for the new generation reared on McKinsey and Co. Inc.

The current demoralization of doctors could not be better exemplified than by the contribution of Professor Peter Huntingford, who confirmed that he had no role. When asked the implications of rejecting the role of the doctor as the leader of the team, he replied, 'I am unable to answer questions such as "what do you like done in this situation?" It leads to tensions and anxieties amongst my junior staff. I regret that for their sakes, but I am not going to stop rejecting the role of doctor; my junior colleagues must come to terms with their own anxieties'. One welcomes the intentions of C.I.B.A. to invite groups of distinguished people to come together to discuss defined subjects and to make constructive comments. It is more difficult to see their purpose in preparing a symposium which incorporates papers of considerable merit upon such disparate subjects as change, re-organization, university health, society, shortened hospital stay, the nurses contribution, quandaries of the health visitor, academic research, cancer and postgraduate training. It is the reviewer's sincere belief that had a medical Mrs Beeton been their adviser she would have thought out her symposium in such a way, that it concentrated upon one or at most three of these subjects rather than spread it over a dozen. If it was a main purpose of the symposium to prepare a subsequent report which might be influential in respects of the changing health needs in the U.K., then there is little doubt that the time of the busy and distinguished people who were the participants would have been better used in the consideration of a more clearly defined area of need. Their subsequent report might then have had considerable impact for there is no doubting of the talent of the contributors. As it is the cooks have had to work very hard to make the gravy.

\section{Hematologic Diseases. New Directions in Therapy}

By Peter Curt Ungaro. Pp. 255, soft cover. Henry Kimpton Publishers, London, 1976. £7.50.

This is an interesting book in a delightful style and format, which sets out to describe the management of blood disorders. Not surprisingly in a single-author book some sections are much better than others. There is an excellent account of management of haematological malignancies, although the section on acute myeloid leukaemia largely ignores problems of sterile environments for patients and related measures to reduce the incidence of infection.

What the author calls 'building block deficiences' is discussed in nine pages which is not much when it embraces iron, $B_{12}$, folate, as well as the minor deficiencies such as pyridoxine, ascorbate, etc. Two short paragraphs are all that are devoted to parenteral iron administration. There is no attempt to discuss particular problems in childhood or during pregnancy. Perhaps there are no such problems in the U.S.A., and these are problems of developing and declining countries.

Nevertheless, this is in many respects an admirable book which students at all levels will find not only useful but a pleasure to read.

\section{An Introduction to Mechanisms in Pharmacology and Thera-} peutics

By Howard Rogers, Roy SPector, with contributions by John Trounce. Pp. 411, illustrated, hard cover. William Heinemann Medical Books Ltd, London, 1976. £7.50.

This book is welcome at a time when there are increasing demands on teachers of pharmacology to interpret the actions of drugs in terms of our growing understanding of molecular biology. It is not a book of systematic pharmacology, nor does it claim to be, but attempts, largely successfully, to explain the mechanisms of action of drugs in terms of cell biology on one hand, and the needs of clinical medicine on the other. There are a few irritating errors in drug names and typography, but that apart, it is firmly recommended, particularly to honours B.Sc. pharmacology candidates, and to those doing clinical studies and who wish to probe more deeply into the actions of those drugs which they are learning to use.

\section{Modern Topies in Rheumatology}

Edited by Graham R. V. Hughes. Pp. $200+$ viii, hard cover, illustrated. William Heinemann Medical Books Ltd, London, 1976. £8.00.

In his foreword Graham Hughes says that editing this book was 'surprisingly enjoyable'. Well, the same can be said of reading it. Surprising, because rheumatology review books nowadays tend to contain long articles dealing with immunological or biochemical topics in great depth: valuable for those preparing papers on the subject themselves, but dull for the general reader. By contrast, Hughes has persuaded most of his authors to keep within 3000 words (not rigidly: George Nuki's outstanding review of gout and purine metabolism is rightly allowed more space) and the result is a series of papers which read like expanded leaders from the medical weeklies. The shortness of the chapters has allowed twenty-three to be included in the 200 pages, and the authors -well chosen from both sides of the Atlantic-between them cover all the important growing points in rheumatology.

This book will probably have most appeal for the practising or trainee rheumatologist. It can be read from cover to 